\title{
Особенности строения грядового рельефа в районе озера Мартимъявр (север Кольского полуострова)
}

\author{
Вашков А.А., Носова О.Ю. \\ Геологический институт КНЦ РАН, Anamumbl,vashkov@geoksc.apatity.ru
}

Аннотация. В работе рассмотрены вопросы структуры, генезиса и механизма формирования грядового рельефа конечно-моренных образований, а также особенности дегляциации на севере Кольского полуострова. Конечно-моренные образования фиксируют одну из фаз отступления баренцевоморского потока последнего оледенения в среднем дриасе. Был применен комплекс геологических, структурных и геоморфологических методов. Установлено, что грядовый рельеф сложен ледниковыми отложениями (абляционным и базальным тиллом), залегающими в виде складок и надвигов. Анализ текстур тиллов и ориентировки элементов гляциодислокаций указывает на передвижение ледника в восточном и северо-восточном направлении. Особенности геологического строения и морфологии грядового рельефа позволили выявить закономерности в плановом расположении отдельных ледниковых форм в виде цепочек гряд. Полученные результаты позволили сделать вывод о механизме формирования ледникового рельефа и о типе дегляциации территории.

Ключевые слова: конечно-моренные образования, моренная гряда, гляциодислокации, базальный тилл, абляционный тилл, флювиогляциальные отложения, дегляциация, ледниковая осцилляция

\section{Structural features of the ridge relief in the Martimyavr Lake area (north of the Kola Peninsula)}

\author{
Vashkov A.A., Nosova O.Yu. \\ Geological Institute of Kola Scientific Centre of RAS, Apatity,vashkov@geoksc.apatity.ru
}

\begin{abstract}
Considered below are issues of structure, genesis and formation mechanism of end-moraine deposits relief and deglaciation features on the north of the Kola Peninsula. The end-moraine deposits set one of retreat phases of the Barents Sea flow during the last glaciation in the Middle Dryas. Complex of geological, structural and geomorphological methods was used in this work. It was determined that the ridge relief is composed of glacial deposits (ablation and lodgement tills) lying in forms of folds and thrusts. Structure analysis of the tills and orientations of the glaciodislocation elements indicate that glacier moved to the east and north-east. Features of geological composition and ridge relief morphology allowed to reveal regularities in a plane location of some glacial forms as ridges rows. The obtained results permitted to make a conclusion about forming mechanism of the glacial relief and deglaciation type of this area.

Key words: end-moraine deposits, moraine ridge, glaciodislocations, lodgement till, ablation till, fluvioglacial deposits, deglaciation, glacier oscillation.

Среди аккумулятивных ледниковых образований Кольского региона особое положение занимает грядовый рельеф, составленный многочисленными формами сложного планового рисунка. Он характеризуется сочетанием невысоких, извилистых в плане, валообразных гряд и разделяющих их изометричных понижений с озерными или заболоченными котловинами. Гряды имеют различную форму: спрямленную, подковообразную, S- образную и замкнутую в кольцо или овал. Отдельные гряды расположены параллельно друг другу или выстраиваются в выраженные цепочки.

В северной части Кольского полуострова, в районе оз. Мартимъявр (бассейн р. Воронья) грядовый рельеф сложной конфигурации встречается в виде выраженных полос шириной от 2 до 25 км, протяженностью 50 и более километров. Здесь он относится к конечно-моренным образованиям (Евзеров и др., 1993; Евзеров, 2015; Kolka et al., 2008). Выявленные в структуре гряд надвиговые и складчатые гляциодислокации указывают на участие в образовании «грядово-ячеистого» рельефа активного ледника. Формирование линейно ориентированного рельефа было связано с внешней полосой поясов краевых образований, на стыке активного и мертвого льда (пояс II). Эти краевые образования были отнесены к среднему дриасу (Евзеров, 2015).
\end{abstract}


Территория района исследования относится к Мурманскому блоку кристаллического фундамента, представленного здесь плагиогранитами, гранодиоритами и лейкогранитами вороньинского и центральнокольского комплексов. Поверхность коренных пород имеет глубину расчленения до 80-100 м, в её структуре выделяются выраженные поднятия, которые в современной поверхности проявляются в виде крупных холмов-массивов. Поднятия разделяются платообразными участками и вытянутыми ложбинообразными понижениями, в пределах которых в современном рельефе часто выражены крупные озерные котловины.

Четвертичные образования района работ имеют мощность от 1-2 м на платообразных участках и вершинах холмов-массивов, до 20-25 м в пределах понижений кристаллического фундамента. Отложения представлены преимущественно ледниковыми аккумуляциями: базальными и абляционными тиллами, флювиогляцильными отложениями, а также осадками современных озер, болот, рек. Ледниковые отложения строят собой гряды, развитые в пределах полосы шириной 2-4 км и длиной до 65-70 км. Полоса имеет в целом субмеридиональное простирание, протягивается от района п. Териберка через понижения кристаллического фундамента с современными озерами БорисЯвр, Перхъявр, Сейдъявр, Лямтъявр, Мартимъявр. Далее прослеживается к югу до котловины озера Ровесъявр, где сочленяется с полосой подобного рельефа субширотного простирания.

В ходе исследования геологическими методами было изучено 11 искусственных обнажений (карьеры, расчистки на склонах гряд, шурфы). Проводилось подробное изучение структурнотекстурных особенностей ледниковых и водно-ледниковых осадков. Отмечались их цвет, гранулометрический состав, текстуры и наличие отдельных слоёв, линз, вкраплений. Производились замеры мощности отдельных слойков и линз, а также азимут и угол падения слоистости. Для подтверждения генезиса и определения направлений нагнетания обломочного материала ледником применялся структурный метод массовых замеров плоскостных (плоскости сланцеватости, слоистости) и линейных (длинные оси галек и валунов) элементов тилла (Аболтиньш, 1989). Геоморфологические методы заключались в сопоставлении геологических данных с формами рельефа, а также в морфометрических исследованиях форм рельефа.

Анализ геологической и структурной информации показывает участие в строении гряд нескольких типов гляциоструктур, которые построены как базальными ортотиллами, так и флювиогляциальными отложениями. Гляциоструктура надвигового типа была известна ранее в небольшом карьере у дороги Мурманск - Туманный (Евзеров и др., 1993; Евзеров, 2015; Kolka et al., 2008). Здесь вскрыто строение гряды субмеридионального простирания, длинной около 0.18 км, шириной 20-35 м, с плоским гребнем и короткими, крутыми склонами. В строении гряды, под покрышкой абляционного тилла (мощностью до 1.2 м) в основном участвует типичный для Кольского региона базальный тилл (Евзеров, 2017; Семенова, 2004), представленный мелкозернистым, глинистым песком зеленовато-серого цвета с гравием, галькой и валунами. Этому тиллу свойственна сланцеватость и тонкая слоистость за счёт прослоев песка мелкозернистого, светло-серого, промытого. Характер падения сланцеватости и слоистости изменяется в разных частях разреза. В западной части они отчетливо наклонены по азимуту $255-275^{\circ}$, под углами $15-30^{\circ}$. В направлении центра гряды угол падения постепенно возрастает до $35-40^{\circ}$. Смена характера залегания тилла происходит непосредственно ниже наиболее отчетливого прослоя песка светло-серого, где сланцеватость и слоистость образует ассиметричную складку. Западное крыло и замковая часть этой складки, залегает непосредственно под прослоем песка светло-серого, а восточное крыло наклонено уже в обратную сторону, согласно восточному склону гряды (азимут падения $75-90^{\circ}$, угол падения $20^{\circ}$ ). Таким образом, базальный тилл этой гряды смят в два типа гляциоструктур: гляционадвиг, формирующий западный склон и гребень гряды и ассиметричную гляциоскладку восточного склона гряды.

Гляциоструктура другого типа была установлена в карьере в 0.6 км к юго-востоку от о3. Мартимъявр. Им вскрыта серпообразная гряда длиной 0.14 км, шириной 10-14 м, высотой 2-4 м. В строении гряды установлены две пачки отложений, залегающие несогласно. В первую пачку входят флювиогляциальные отложения (рис. 1, слои 1-2), которые представлены грубыми печсаногравийными смесями с валунами и песками разнозернистыми, слабой степени сортировки, без ви- 
димой слоистости. Эти аккумуляции развиты только на восточном склоне гряды, где их мощность составляет более 2.5 м. С запада на них надвинут флювиогляциальный материал второй пачки. Зона контакта двух пачек падает по азимуту $237^{\circ}$ и под углом $68^{\circ}$, флювиогляциальный материал вдоль зоны контакта сцементирован железистым цементом и имеет ржаво-коричневый цвет. Отложения второй пачки залегают в виде ассиметричной складки. На крыльях и в замковой части складки развит флювиогляциальный материал (рис. 1, слои 3-6), который состоит из переслаивания гравийногалечной смеси с валунами, плохо сортированной с песчано-гравийной смесью и песком разнозернистым, промытым. Падение переслаивания этих осадков на западном крыле складки отмечается в юго-западных румбах (азимуты от $236-246^{\circ}$ ) под углами от $38^{\circ}$ до $68^{\circ}$. В замковой части залегание слоев облекающее относительно ядра складки. На восточном крыле флювиогляциальные отложения залегают запрокинуто. Общая мощность флювиогляциальных аккумуляций составляет от 0.3-0.6 м в замковой части до 1.4-2 м на крыльях складки. Восточное крыло складки осложня-
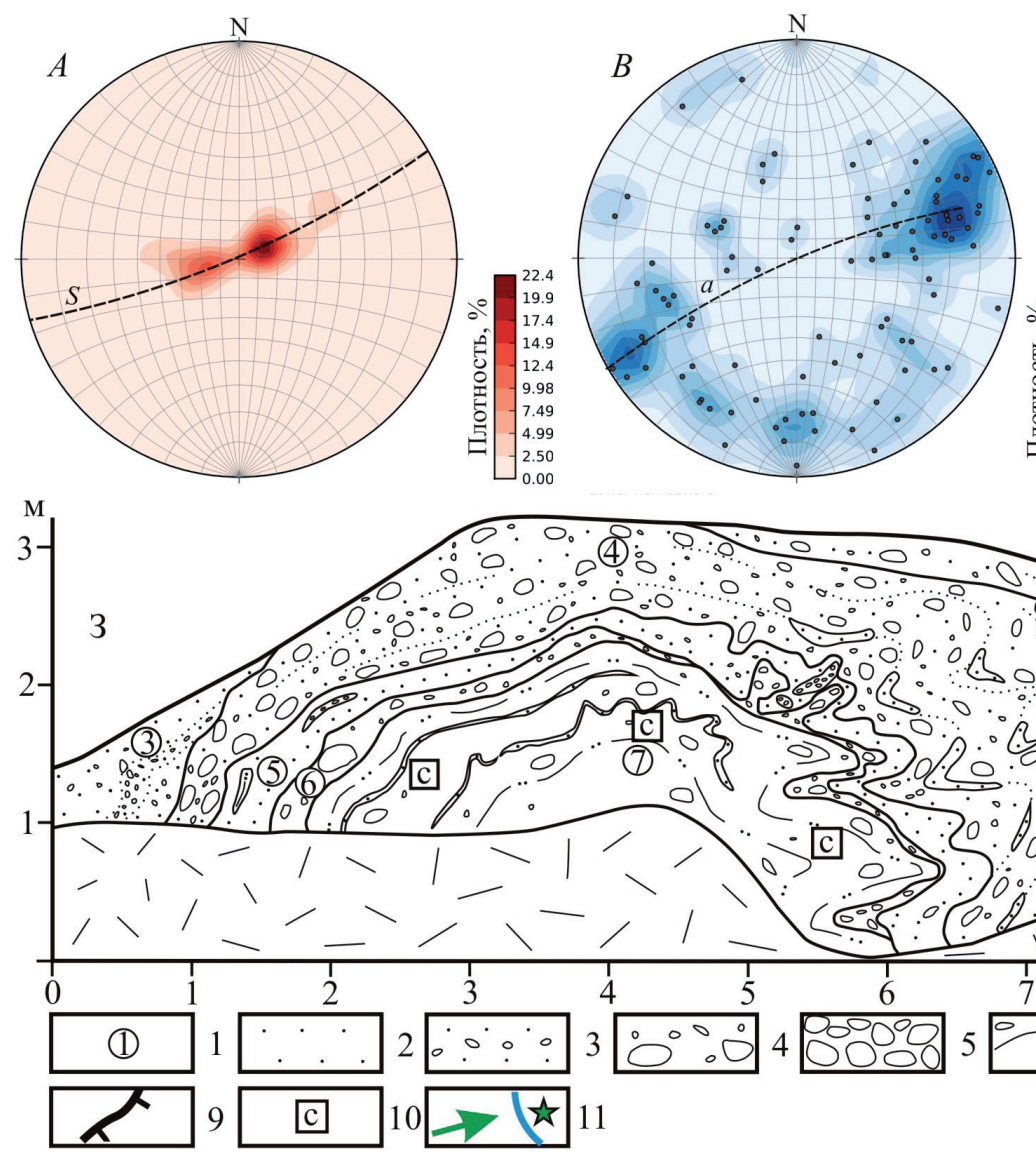
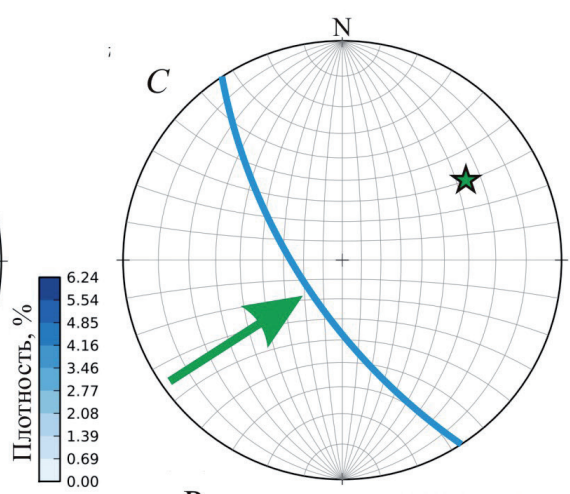

Равноугольные проекции на нижнюю полусферу

1 - номера слоев; 2 - песок разнозернистый; 3 - песчано-гравийная смесь; 4 - гравийно-галечная смесь; 5 - галечно-валунная смесь; 6 - песок зеленовато-серый с галькой и валунами; 7 - песок разнозернистый в линзах; 8 - направление падения слоистости; 9 - плоскость надвига; 10 - места структурных исследований песков в ядре складки; 11 - направление давления ледника, проекция и падение полюса плоскости надвига. Буквами обозначены структурные диаграммы: А - падение полюсов слацеватости и слоистости в складке; В - падение линейных элементов в складке; С - падение плоскости надвига

Fig.1. Composition of the ridge with difficult plane orientation in the section № 2.

1 - layer numbers; 2 - various-grained sand; 3 - sand-gravel mix; 4 - gravel-pebble mix; 5 - pebble-boulder mix; 6 - greenish gray sand with pebbles and boulders; 7 - various-grained sand in lenses; 8 - dip direction of lamination; 9 - thrust plane; 10 - areas of structural studies of sands in the fold core; 11 - pressure direction of glacier, projection and dip of thrust plane pole. Letters denote structural diagrams: A - dip of foliation and lamination poles in the fold; $\mathrm{B}$ - dip of linear elements in the fold; $\mathrm{C}$ - dip of thrust plane. 
ется многочисленными острыми, клинообразными лежачими микроскладками, с высотой крыльев до 0.7 м. Осевые плоскости микроскладок расположены субгоризонтально. Ядро складки построено деформированным базальным тиллом мощностью более 1.8 м. Он представлен песком мелкозернистым, глинистым, с валунами, зеленовато-серого цвета, с тонкой сланцеватостью и слоистостью. Структурный анализ плоскостных элементов сланцеватости и слоистости глинистых песков обнаруживает распределение максимумов ориентировки в виде изогнутого пояса (рис. 1, А). Направление планового рисунка указывает на падение западного крыла складки по азимуту $239^{\circ}$ и восточного крыла по азимуту $78^{\circ}$. Падение шарнира складки установлено под углом $5^{\circ}$ в юго-юго-восточном направлении по азимуту $162^{\circ}$. Такой плановый рисунок падения плоскостных элементов гляциострукруты характерен коническим гляциоскладкам (Аболтиньш, 1989).

Анализ строения ледниковых гряд района работ в шурфах и расчистках подтверждает преобладание в их строении базальных тиллов, которые залегают преимущественно в виде складчатых гляциоструктур. Осадки абляционного тилла залегают, как правило, облекающее, и не имеют ведущего рельефообразующего значения. Флювиогляциальные аккумуляции также могут включаться в состав складчатых гляциоструктур, однако, в районе работ выявлены и гряды, построенные исключительно этими отложениями. Такие гряды имеют обычно субширотную ориентировку. Флювиогляциальные осадки представлены галечно-гравийными смесями с валунами средней и хорошей степени окатанности и разнозернистым песком плохой степени сортировки. Подобный по составу флювиогляциальный материал выявлен и в строении гряд-увалов с плоскими вершинами восточнее участка развития моренных гряд. Западнее зоны грядового рельефа расположена моренная равнина. Она представлена ледниковыми отложениями абляционного и базального тиллов небольшой суммарной мощности до 1-3 м. Базальным тиллам моренных равнин характерна тонкая сланцеватость и слоистость с уклонами под углами $10-15^{\circ}$ и падением в южных румбах (азимуты $157-174^{\circ}$ ).

Морфометрический анализ и плановое расположение гряд в районе оз. Мартимъявр показывает, что наиболее высокие и протяженные гряды, выраженные в рельефе за счёт надвиговых и складчатых гляциоструктур, выстраиваются в линейно вытянутые цепочки, которые прослеживаются параллельно друг другу. Всего в районе работ установлено не менее шести параллельных цепочек. Эти фронтальные гряды фиксируют краткосрочные подвижки (осцилляции) активного края ледника. Такие гряды обладают максимальной длиной и высотой, а также наиболее крутыми склонами. Между фронтальными расположены кольцевые гряды подковообразной, S- образной и округлой формы (в плане), которые отличаются меньшей длиной (до 125 м) и высотой (до 3.5-4 м). Субширотно ориентированные гряды, построенные флювиогляциальными осадками отнесены нами к типу радиальных гряд. Эти гряды, как правило, спрямленные или слабоизвилистые, часто прослеживаются вдоль современных речных долин. Восточнее участка распространения фронтальных и кольцевых гряд прослеживается прерывистая полоса гряд-увалов, которые далее в направлении долины р. Воронья сменяются расчлененным рельефом коренных пород с отдельными холмамимассивами и площадками долинных зандров в понижениях.

Таким образом, изучение морфологии и геологического строения грядового рельефа в районе котловины озера Мартимъявр позволило определить особенности ледникового морфогенеза на севере Кольского полуострова. Установлено, что формирование ледниковых гряд района работ связано с активным гляциотектоническим воздействием на рыхлые породы ложа и перенасыщенный дебрисом лёд. Ядра большинства гряд построены складчатыми, надвиговыми гляциоструктурами, или их сочетанием. Гляциоскладки возникали при устойчивом сжимающем давлении на рыхлые породы, которые выдавливались в ослабленные зоны ледникового покрова в его краевой зоне. При увеличении давления со стороны активного льда, продвигающегося в северо-восточном направлении, возникали гляционадвиги. Небольшая ширина участка распространения грядового рельефа означает незначительные колебания края активного ледника в пространстве и указывает на фронтальную дегляциацию территории. Таким образом, ареальная дегляциация на севере Кольского полуострова с отмиранием крупных частей ледникового покрова сменялась здесь периодами относи- 
тельной стабилизации активного ледникового края. Полученные результаты будут использованы в дальнейших работах по установлению особенностей ледникового морфогенеза и особенностей динамики последнего ледникового покрова в Кольском регионе.

Работа выполнена по теме НИР 0226-2019-0054 лаборатории №43 геологического института КНЦ РАН

\section{Литература}

1. Аболтиньш О.П. Гляциоструктура и ледниковый морфогенез. Рига: Зинатне. 1989. 284 с.

2. Евзеров В.Я. Горбунов Е.О., Колька В.В. Краевые ледниковые образования позднего дриаса в северной и центральной частях Кольского полуострова // Четвертичные отложения и новейшая тектоника ледниковый областей Восточной Европы. Апатиты. 1993. С. 26-38.

3. Евзеров В.Я. Литология морены поздневалдайского оледенения западной части Кольского полуострова // Вестник Мурманского государственного технического университета. 2017. Т. 20. № 1-1. С. 48-59.

4. Евзеров В.Я. Строение и формирование внешней полосы одного из поясов краевых образований поздневалдайского ледникового покрова в Кольском регионе // Вестник Воронежского государственного университета. Серия: Геология. 2015. № 4. С. 5-12.

5. Семенова Л.Р. Ледниковая геология Кольского полуострова (поздний плейстоцен) // Автореферат диссертации на соискание ученой степени кандидата геолого-минералогических наук по специальности 25.00.01 - Общая и региональная геология: СПб. ВСЕГЕИ. 2004. 23 с.

6. Kolka V., Korsakova O., Nikolaeva S., Yevzerov V. The Late Pleistocene interglacial, late glacial landforms and Holocene neotectonics of the Kola Peninsula // ICG excursion. №34. August 14-23. 2008. 72 p. 